\title{
LA PARADOJA DEL REFORMISTA
}

THE REFORMIST PARADOX

\section{EDUARDO MÍGUEZ ·}

Docente e investigador de la Universidad Nacional del Centro de la Provincia de Buenos Aires y de la Universidad Nacional de Mar del Plata (Argentina).
Tres comentarios, tres temas diferentes. ¿Pero no es posible encontrar una clave que unifique las agudas intervenciones de los tres calificados comentaristas? Antes de intentarlo, debo agradecer su gentileza. Decía en la introducción que antes de la mesa redonda tenía la esperanza de recibir algún elogio. Sus textos fueron más allá de mi previsión, incluso en ese sentido. Solo puedo esperar que el libro sea realmente digno de esos halagos, que solo me queda agradecer.

\section{Registro bibliográfico}

MÍGUEZ, EDUARDO "La paradoja del reformista», en: ESTUDIOS SOCIALES, revista universitaria semestral, año XXIX, n 56, Santa Fe, Argentina, Universidad Nacional del Litoral, enero-junio, 2019, pp. 247-254.
El desafío, sin embargo, es recoger las observaciones y comentarios menos complacientes, y pensarlos en relación al texto. Para intentarlo, puede partirse de una paradoja notable. Cuando alguien se propone transformar la sociedad a través de la acción política, choca con un problema difícil de resolver. Para actuar eficazmente hay que tener poder. Pero es muy difícil construir poder sin apelar a las mismas formas sociales que se busca transformar. Y si uno se sirve de ellas, más que trans-

\section{Descriptores · Describers}

Bartolomé Mitre / biografía / reformismo Bartolomé Mitre / biography / reformism

Recibido: 28/09/2018 Aceptado: 03/12/2018 
formarlas, la refuerza ${ }^{1}$. Así, si no el quietismo, parece predominar la inercia. El desarrollo de los procesos, incluso de los cambios, sigue un curso que parece más inscripto en la naturaleza misma de las cosas, que en la voluntad de los actores.

¿Desaparece entonces la agencia de los individuos? Desde luego que no. Por un lado, porque parte de la realidad dada es el resultado de la acción humana conciente, voluntaria, orientada. En la lenta construcción de contextos de cambio, la arquitectura de ideas y propuestas que alteran el orden social tiene una gradual incidencia. Refiriéndonos ya al contexto que nos interesa, el cambio en la forma de entender las relaciones humanas y el orden político que hunde sus raíces en el siglo XVI, que se renueva en el XVII, que en el XVIII intensifica su dialogo con las formas políticas reales, y que el xix eclosiona en la formación de los modernos estados nacionales, es sin duda el resultado de la agencia de quienes fueron pensando y construyendo lo que terminaría siendo el Estado nacional liberal ${ }^{2}$.

Aquí nos interesa, sin embargo, otra forma de intervención, más inmediata, y más directa, a veces, revolucionaria. Esa era la ambición de Mitre. Ese tipo de agencia también es posible, pero el protagonismo depende mucho de la coyuntura. En los momentos de crisis, una intervención afortunada puede orientar la evolución de los acontecimientos en el sentido en que el actor, ubicado en el lugar y el momento justo, busca llevarlos (y una desafortunada, puede descarriar la oportunidad, y orientar a la sociedad por un sendero difícil de desandar). Mitre fue protagonista de muchos momentos así; I852-I853, I859-I862, I868, I880, I889I892. En los dos primeros, y sobre todo, en la conjunción de esos dos momentos, Mitre jugó un papel central -él papel central en I859-I862- incidiendo de manera determinante en el sentido en que se desarrollaron los hechos. En I868 las cosas se le fueron de las manos. En I88o, su papel fue marginal, en 1889-1892, nunca pudo tener verdadero control de la situación.

Un punto importante en el texto de Botana es la tensión entre el Mitre principista, y el Mitre acuerdista. Destaca con acierto que su profunda vocación política lo llevó en varios momentos claves a adop-

1] Además de encontrar esta paradoja en mi labor de historiador, en modesta escala la he sufrido como gestor universitario. Al intentar introducir cambios en el funcionamiento de la universidad, debía apoyarme en los mismos recursos que consideraba necesario cambiar. Sin duda, esta experiencia hace más vívida esta paradoja en mi oficio de historiador.

2] Sin dejar de lado, desde luego, el cambio en las formas productivas, que también es en buena medida emergente de la agencia individual. 
tar políticas de acuerdo. De hecho, esa reiteración, resaltada por el pacto que realizó con Roca en I89I, llevó a afirmar que Mitre tenía una concepción acuerdista de la democracia. Me pareció -y me parecenecesario discutir esa afirmación. Mitre tenía una profunda convicción sobre las virtudes de una democracia popular, y en ese sentido, es muy justa la observación de Sabato, de que su papel como caudillo porteńo no es suficientemente destacado en mi libro. La discusión sobre el acuerdo de I89I con Bernardo de Irigoyen es elocuente. Si la ambición de uno por volver a la presidencia, y del otro por alcanzar el segundo lugar de una fórmula triunfal, sin duda pesa en el intercambio epistolar entre ambos en ese momento, eso no invalida la elocuencia de los argumentos. "General, de acuerdo con sus propias convicciones, vayamos juntos a la contienda electoral tal como decidió la convención de la Unión Cívica, y dejemos que el pueblo decida si debemos gobernar», es el argumento de Don Bernardo. "Así debería ser; pero no habiendo condiciones de libertad electoral, es mejor un acuerdo de cúpulas que asegure un gobierno con vocación democrática, que dejar la cuestión librada a los turbios manejos electorales que han predominado después de mi presidencia», responde Don Bartolo, no sin marcada benevolencia sobre su propio mandato.

Apasionado por un proyecto que consideraba «justo y bueno» -y no dudo de la honestidad de esa convicción- Mitre trabajó con las herramientas a su alcance para intentar concretarlo. No pocas veces, esas herramientas eran exactamente opuestas a sus intenciones. El fraude electoral en I852, y su tolerancia, si no participación activa, en momentos posteriores; mirar hacia otro lado cuando desde su gobierno se apoyaba la invasión de Flores a la Banda Oriental en I863; la "peor de las revoluciones» en I874 son, en ese sentido, puntos oscuros de esa trayectoria. ¿Creía Mitre que la capital debía estar en Buenos Aires? Se opuso en I853 y I860, lo impulsó en I862, vetó la ley que sacaba de allí la capital en I867; un favor a Sarmiento que el sanjuanino (quien un par de años más tarde vetaría una ley similar) no agradeció debidamente. Finalmente, se opuso a la federalización en 1880 . Al igual que la revolución de i874, esto último puede explicarse como un tibio intento por tratar de preservar lo poco que le quedaba de ese liderazgo popular porteño, que perdió inevitablemente por las razones que muy bien explica Gerchunoff. Y que recuperaría, al final de su vida, ya como capital simbólico, no político.

En cambio, la política de acuerdos y transacción no puede cifrarse en el mismo plano. Es perfectamente legítimo lograr acuerdos, para avanzar, aunque sea parcialmente, con los objetivos que el político se propone. Esos acuerdos siempre implican resignar aspectos del programa 
propio. La gran pregunta es cuando se está cediendo tanto, que se pierde totalmente el rumbo de lo que se buscaba. Para un hombre como Mitre, para quien la práctica de la política consistía en la consecución de un programa, es ese un dilema acuciante. La biografía de Mitre muestra las inevitables contradicciones en las que la política práctica lo sumía. A veces, esas contradicciones caben en el durísimo juicio de Gutiérrez que cito al iniciar la tercera parte de mi libro; muchas otras, fueron útiles concesiones que permitieron avanzar con su proyecto. No faltaron ocasiones en que la realidad y sus interlocutores enmendaron sus errores de apreciación, aunque a Mitre siempre le costó admitirlo. En otras, se resignó a aceptar lo que la realidad le imponía, sin dejar de lamentarlo (estoy seguro que el asesinato de Peñaloza cabe en esta última categoría). La interacción entre ideas, proyectos y realidad siempre es compleja y ambigua, y es eso lo que busco reflejar en mi libro, conciente de que esa ambigüedad abre un margen para ver las cosas de manera diferente.

¿Vaso medio lleno, o medio vacío? Mi largo diálogo con Hilda sobre la práctica republicana entre Caseros y 1890 (o 1912), tiene un poco de eso. Seguramente coincidimos en que existe una distancia entre los ideales republicanos de Mitre, y la realidad de las prácticas de sus contemporáneos, y de su propio partido. Por otro lado, ningún régimen político está a la altura de sus ideales. Por cierto, con sus defectos, la trabajosa construcción republicana porteña en la época abarcó la participación de sectores sociales más amplios que las limitadas elites dirigentes ${ }^{3}$. Hilda Sabato ha estudiado esta participación del pueblo (en un sentido amplio); el peso de "la opinión", en varios de sus textos ${ }^{4}$, mostrando en ella las bases de legitimidad de aquel régimen político. Yo he sido más escéptico, en una perspectiva con mayor énfasis fuera de la gran ciudad. Mitre, que era un entusiasta y un optimista, veía en esas multitudes que no pocas veces lo aclamaron frente a su casa la expresión del fervor popular. Pero como también era una mente crítica, sabía, como expresa su carta a Irigoyen de I89I, y tantos otros textos, que difícilmente los resultados electorales expresaran de manera transparente la voluntad popular, y que ello corroía lo que Botana ha llamado con justeza la legitimidad de origen del régimen político (BOTANa, [1979] 20I2). Como reformista, Mitre navegaba las inquietas aguas entre lo deseable y lo posible. En una ocasión excepcional, en un

3] Por otro lado, una investigación que desarrollo en la actualidad muestra que estas eran bastante menos cerradas de lo que muchas veces se ha supuesto.

4] Ver, por ejemplo, SABATO (1998; 2008; y 2010). 
discurso parlamentario en 1870, aceptaba alberdianamente ( estamos haciendo la república posible, y vamos en marcha hacia la verdadera república...») esa distancia, que no por ello dejaba de aborrecer. ¿Cuál es el punto de equilibrio? ¿Cuándo las concesiones anulan la eficacia de las reformas? Hilda me ve quizás demasiado pesimista. Yo no diría que el pragmatismo neutralizó cualquier reforma. Si, en cambio, que en relación al proyecto, los resultados fueron siendo bastante (o un poco) decepcionantes. Si se mira, en cambio, en la perspectiva del punto de partida, el avance democráticorepublicano distó mucho de ser nulo. Es comprensible que siglo y medio después los historiadores sigamos tensionados por encontrar un juicio equilibrado sobre aquella república, aquella democracia, que continúan siendo en parte esquivas.

Que el pequeño y delicioso bosquejo de ensayo de Pablo Gerchunoff encuentre menos fricción con los argumentos de mi Mitre se debe seguramente a que el punto de mira que eligió para su comentario es muy afín a uno de los observatorios centrales de mi texto. La versión canónica sobre los meses que van de setiembre de I86I a octubre de I862 (o noviembre del año siguiente, si deseamos incluir el asesinato de Peñaloza) me resulta totalmente insatisfactoria. Si Mitre logró cerrar (o al menos, comenzar a cerrar) la brecha que separaba a Buenos Aires de las provincias, fue, como bien perciben Gerchunoff y Botana, por su vocación negociadora, no por el abuso de la fuerza; aunque desde luego, la fuerza no estaba ausente de esa negociación. Fue también porque encontró en las elites «liberales» del interior una contraparte mucho menos débil de lo que pretendía ser. Llamarse liberales era adoptar un ropaje cómodo en aquel momento, incluso para quienes -incluyendo a los Taboada, abuelos del Mitre de Santiago del Estero que tan felizmente recobrara Pablo- habían habitado sin titubeos el proyecto urquicista hasta que este mostró su escasa viabilidad. Ser débiles, eximía de obligaciones, y permitía demandas. Quienes apoyaron a Mitre en el interior fueron en muchos casos los mismos protagonistas centrales del proyecto urquicista.

Pero esa construcción exigía fuertes sacrificios a Buenos Aires. La desesperación del ortodoxo financista Norberto de la Riestra por la emisión sin respaldo que demandaba -y que Mitre ya previera antes de Pavón- es la más elocuente muestra de esa transacción. El argumento de Pablo: «imposible construir la nación sin socavar el poder en la base porteña» es la ajustada conclusión a uno de los temas que vertebran la obra.

En I874, I880, y también quizás en I890, que es, entre otras cosas, una rebelión porteña contra un presidente cordobés, Mitre volvería a alinearse con su provin- 
cia adoptada. ¿Y en I868? ¿Apoyó al muy porteño Elizalde, no solo para conservar el poder en su partido, sino también en su ciudad? Estoy seguro que Elizalde estaba convencido que ese apoyo fue demasiado reticente. Como sugiere Gerchunoff, fue mucho lo que Mitre concedió a las provincias, no solo en lo económico, sino también en poder. Avellaneda fue hijo de Sarmiento y padre de Roca, que a su vez, engendró a Juárez 5 . Recién al salir de la crisis de 1890 , en aquel difícil quinquenio que evocara Ezequiel Gallo -y ya sin el poder del Banco Provincia, nos recordaron Gerchunoff, Rocchi y Rossi- pareciera que la confrontación Buenos Aires/ interior pierde su fuerza (GALlo, I980; GERCHUNOFF, ROCCHI Y ROSSI, 2008). Pero para Mitre ya era tarde; su destino era derrotar a Platense (el equipo del Plata), en representación de Santiago del Estero. Y pese a ello, como señala Pablo, no poder llegar nunca a mascarón de proa en la representación del interior. Hoy, seguramente, ese sacrificio porteño en aras de la nación genera menos reparos que el fraude electoral, el intento revolucionario, o la intervención en conflictos políticos internos de los vecinos. Visto, en cambio, en la perspectiva de entonces, fue una cru- cial concesión, seguramente inevitable, pero igualmente costosa, en el programa de Mitre. Y de poderosas consecuencias. Una nación porteñocéntrica hubiera sido muy diferente de la actual Argentina, como se deduce del bosquejo de Pablo.

Más allá de las tensiones prácticas de un reformista, Natalio nos propone un argumento más trascendente. Si lo entiendo bien, hasta cierto punto Mitre se vería a si mismo, como vio a Belgrano y a San Martín (y también a Bolívar), como protagonistas centrales en la construcción de un proyecto que los sobrepasa, y al que sirven incluso cuando se alejan, por convicción o necesidad, de ese mismo proyecto (y en cierta forma, lo mismo harían sus rivales) ${ }^{6}$. ¿Sus esfuerzos avanzan un programa que está destinado de todas maneras a cumplirse, y sus concesiones y negociaciones, en definitiva, nunca podrán desviar el rumbo ya marcado a la nave por la historia? En cierta forma, no dudo que sea así. Mirando al Mitre político, no ya al historiador, se lo ve con una muy decimonónica convicción de que no es más que un agente de la historia (un gran agente, por cierto), destinado a cumplir su destino. Su sentido de misión «admirándome yo mismo de mi coraje,

5] No me refiero aquí al presidente como gran elector, si no a la trabajosa trama de construcción de alianzas provinciales que se dieron progresivamente en estas presidencias.

6] Sobre los proyectos de nación en esta etapa, y sus tensiones, ver BOTANA y GALLO (1997). 
de pretender formar una argentina (como la he de forma) con tales elementos, y tales cooperadores...» (p. 219) era poderoso. En su momento protagónico, entre I860 y i865, según traté de argumentar en la segunda parte de mi trabajo, Mitre asume un protagonismo muy personal; ¿recordaría las expectativas y dudas de su juventud, que reflejara en su diario?7. ¿Preservaría esa confianza cuando ya no era tan evidente que su papel fuera protagónico en la construcción de su proyecto?

Las preguntas que esto abre en el campo de la historia intelectual son desafiantes. ¿Como comparar la sociología de Mitre, tan imbuida de un sentido de destino, posible que ni siquiera conversando con con la visión más pragmática de Alberdi, Mitre se pudiera encontrar respuesta a o la más pesimista y descarnada (y más esas preguntas. versátil, según Halperín ${ }^{8}$ ) de Sarmiento? Y también en el plano biográfico. ¿Mitre tendría la ventaja sobre sus biografiados de ser plenamente conciente de lo que estaba haciendo? ¿No lo asaltarían dudas, al tomar sus decisiones más controversiales, sobre si realmente eso era lo mejor que podía hacer en ese momento? ¿La convicción sobre el futuro lo eximía de responsabilidad? La desdicha del biógrafo de Mitre, es que la certeza final en estas dudas solo sobrevendría con ese diálogo imposible que uno no deja de imaginar cada vez más intensamente a medida que avanza en su trabajo. O quizás no. Es
7] «Yo me siento con grandes aspiraciones y tengo la pretensión de creer que existe en mí el germen de alguna cosa. iY Dios quiera que no me engañe! Pero si esto sucede ¿como ha de ser?» (MITRE, 1959: 12). 8] Ver al respecto HALPERIN DONGHI (1993). 


\section{Referencias bibliográficas}

BOTANA, NATALIO R. ([1979] 2012): El orden conser- HALPERIN DONGHI, TULIO (1993): «De voluntades y vador. La política argentina entre 1880 y 1916, realidades», en: Ciencia Hoy, nº 18.

Buenos Aires, Edhasa.

BOTANA, NATALIO Y GALLO, EZEQUIEL (1997): De la República posible a la República verdadera (1880-1910), Buenos Aires, Ariel.

GALLO, EZEQUIEL (1980): «Un quinquenio difícil», en Ferrari, G. y Gallo, E. (comps.), La Argentina del '80 al Centenario, Buenos Aires, Sudamericana. GERCHUNOFF, PABLO, ROCCHI, FERNANDO Y ROSSI, GASTÓN (2008): Desorden y Progreso. Las crisis económicas argentinas (1870-1905), Buenos Aires, Edhasa.
MITRE, BARTOLOMÉ (1959): «Diario de Juventud», en: Obras Completas, t. XIII, Buenos Aires, Congreso de la Nación.

SABATO, HILDA (1998): La Política en las Calles. Entre el voto y la movilización. Buenos Aires, 1862-1880, Buenos Aires, Sudamericana.

SABATO, HILDA (2008): Buenos Aires en Armas, Buenos Aires, Siglo XXI.

SABATO, HILDA (2010): Pueblo y Política, Buenos Aires, Capital Intelectual. 